\title{
Conversion Messages and Attitude Change: Strong Arguments, Not Costly Signals
}

\author{
Benjamin A. Lyons \\ University of Exeter \\ b.lyons@exeter.ac.uk \\ Ariel Hasell \\ University of Michigan \\ Meghnaa Tallapragada \\ Clemson University \\ Kathleen Hall Jamieson \\ University of Pennsylvania \\ Conditionally Accepted at Public Understanding of Science
}

\section{Acknowledgements}

The authors acknowledge Jeremy Quattlebaum for video editing, William K. Hallman for comments on design, and Scott Hamilton Kennedy for advance copy of the film Food Evolution.

\section{Funding}

This work was supported by the 'Science of Science Communication' initiative of the Annenberg Public Policy Center at the University of Pennsylvania. This project has also received funding for Lyons' time from the European Research Council (ERC) under the the European Union's Horizon 2020 research and innovation programme [grant agreement number 682785]. 


\begin{abstract}
A conversion narrative recounts the process that led the speaker to reject one belief for a different, usually incompatible, alternative. However, researchers know little about whether, when, and, if so, how such messages affect audience attitudes about controversial science. Using a general U.S. population-sample experiment, we assessed the attitudinal impact of three versions of a statement by Mark Lynas, an environmental activist who converted from opposing to championing genetically modified crops. Participants were exposed to 1) a one-sided pro-GM message by Lynas; 2) a twosided pro-GM message in which Lynas indicates but does not detail his conversion or 3) a twosided pro-GM message in which Lynas explains the process that prompted his conversion. We find that his conversion messages influenced attitudes by way of perceived argument strength, but not speaker credibility. This finding implies such messages induce greater elaboration, which may lead to durable attitudes that predict behavior.
\end{abstract}

Keywords: Conversion message, persuasion, argument strength, costly talk, credibility 
Conversion Messages and Attitude Change:

Strong Arguments, Not Costly Signals

Public understanding of science is often impeded by the influence of social group affiliations (Hornsey and Fielding, 2017; Nauroth et al., 2017; Nisbet et al., 2015). In “the competition of voices reaching the individual" (Campbell, Converse, Miller, and Stokes, 1960, p. 128), individuals often embrace "facts" favoured by fellow group members, polarising beliefs about a number of scientific issues (Pasek, 2017; Veenstra et al., 2014). A variety of group identifications, including partisanship, religious affiliation, and environmentalism (Drummond and Fischhoff, 2017; Kahan et al., 2011; Pasek, 2017; Veenstra et al., 2014; 2016), contribute to these belief gaps. In other words, gaps between scientific consensus and personal belief in these cases are not information deficits but instead are motivated rejections — an issue of trust and credibility accorded to experts and findings that conflict with group values (Bauer, 2009). Those responsible for messaging in such contexts must be conscious of this fact, and select messengers and content accordingly.

To overcome these group influences on attitudes toward contested science, individuals and organisations turn to a variety of rhetorical devices (Hornsey and Fielding, 2017). One form of argument communicators rely on in these contexts is the conversion message. A conversion message recounts the process that led the speaker to reject one belief for a different, usually incompatible, alternative. Examples of public-facing conversion messaging regarding contested science include conversions from anti- to pro-vaccine (Voices for Vaccines, n.d.); climate skeptic to climate believer (The Guardian, 2018; Pomeroy, 2018); anti- to pro-nuclear energy (Madrigal, 2007; Schellenberger, 2017); and as examined in the present research, anti- to pro-genetic modification (Storr, 2013).

Research centring on intergroup and intra-group communication dynamics (Djupe \& Gwiasda, 2010) suggests these conversion messages may be an effective persuasive technique. 
However, the actual effects of such messages remain unknown. We undertake the first test here, the results of which may better inform strategic communication campaigns and provide a fine grained exploration of this popular form's pathways to influence over attitudes toward controversial science. ${ }^{1}$

We test our hypotheses using a general population-sample experiment in the United States. Our focus is the debate surrounding the safety of genetically modified (GM) crops. We test excerpts of an actual conversion message, delivered by a science writer and environmental activist, that details a transformation from anti- to pro-GM advocate. Conversion messages led to significantly more attitude change compared with a one-sided advocacy condition. We find that perceived argument strength, and not enhanced speaker credibility, accounts for this effect. In the following sections, we provide an overview of the theory behind our hypotheses by explaining potential mechanisms that could account for the attitudinal effects of conversion messages.

\section{Conversion message as persuasive technique}

Persuasion researchers frequently overlook content, focusing instead on extrinsic factors such as source and recipient characteristics. When messages are examined, researchers tend to focus on sidedness or order rather than the nature of the messages themselves (Slater and Rouner, 1996). This neglect of content has been called "the most serious problem in communication and persuasion research," (Fishbein and Ajzen, 1981, p. 359). Despite calls to address the issue (Johnson, Maio, and Smith-McLallen, 2005; McGuire, 2000; O’Keefe, 2002; Reynolds and Reynolds, 2002), scholars' understanding of the effects of the content of arguments remains rudimentary (Hoeken and Hustinx, 2009). Although scholars of rhetoric describe an array of techniques that strategic

\footnotetext{
${ }^{1}$ We do not make a normative case for the value of the conversion message, but rather examine this common rhetorical form's effects and mechanisms through which these occur. In practice, it should be noted that such messages may be employed to overcome group influence to either improve, or ultimately worsen, public understanding of science.
} 
communicators may employ, ${ }^{2}$ the functioning and effects of many have yet to be studied empirically (Vancil 1993; Slater \& Rouner, 1996). In this study, we empirically test a durable (Caldwell, 1983) rhetorical form, the conversion narrative.

An individual's “conversion" may be rooted in a transformative experience, a thoughtful reconsideration of the facts, or some combination of the two. ${ }^{3}$ Regardless of the domain, there seems to be something powerful about a conversion. For this reason, such messages appear to be common in public discourse. ${ }^{4}$ Although scholars have examined the rhetoric of conversion messages (Booth, 1995; Caldwell, 1983; Fredriksen, 1986; Hindmarsh, 2005; Stromberg, 1993), they know little about whether, when, and if so how they influence attitudes at play in a debate over controversial science.

Despite, or perhaps because of the prevalence of conversion messages in popular culture and strategic communication, the perception of their effectiveness is based upon conventional wisdom, with surprisingly few empirical tests in persuasion research or other related communication literatures. While it is plausible that such messages are persuasive, the size of the effect and their mechanism are unclear. In this study, we advance and test two hypotheses that explain why conversion messages are effective.

\footnotetext{
${ }^{2}$ A few strategies described by rhetoricians but with limited attention from empiricists include the use of strategic ambiguity (Reinemann and Maurer, 2005), Rogerian argument (Lunsford, 1979), casuistic stretching (Longaker, 2012; Zarefsky, 1980), and various uses of enthymeme (Smith, 2007) and paradeigma (Jordan, 1986).

${ }^{3}$ Popular uses of the conversion trope have religious origins (Caldwell, 1983). To provide evidence that their souls had been saved, those seeking to join a Puritan church had to tell the story of their transformation before the congregation. (Caldwell, 1983). "Seeing the light" is now broadly used to describe a range of belief change.

${ }^{4}$ In politics, for example, conversion messages recount personal transformations that occurred "at a particularly opportune time," (Macgillis, 2011). In a notable 1964 ad for incumbent president Lyndon Baines Johnson titled "Confessions of a Republican," an actor explains his defection from the Republican fold (Volle, 2010). Ads containing a voter's rationale for switching parties are common (Bell, 2017; Lyngar, 2014), and tales of personal conversion from bigotry to tolerance on social issues such as racism, homophobia, and sexism populate opinion pages (Elliethee, 2013).
} 
The first potential mechanism of conversion message persuasion is the enhanced credibility that may attach to a person willing to admit to a dramatic change in belief. Those who switch teams to claim a once-derided stance may send a signal that the truth is more important to them than social or financial cost. In other words, the fact of conversion alone could make the speaker appear more trustworthy, regardless of the strength of the justification for the change. Secondly, conversion messages may work through argument strength. The fact that they by definition juxtapose an initial and subsequent stance may prompt closer scrutiny of their arguments. If this is the case, conversion messages may persuade those sharing a group identity with the speaker if the process underlying the shift aligns with the group's values. At the same time, they may persuade others by appearing to provide a carefully considered justification for each claim. Dual process theories of persuasion suggest the difference between these mechanisms matters. Greater elaboration (e.g., scrutiny of argument strength) leads to more durable attitudes that are more predictive of behavior (Greenwald and Leavitt, 1984; Petty and Cacioppo, 1986).

\section{Enhanced speaker credibility}

Unexpected positions by a speaker may appear more credible than expected ones (Petty and Cacioppo 1986). Specifically, messages that are costly for a speaker to make are more credible than "cheap talk." For instance, politicians whose messages appear to be damaging to their own party are seen as more credible than those who toe the party line, and the credibility bestowed by such costly messages tends to materialize regardless of the listener's political leanings (Berinsky, 2015; Groeling and Baum, 2008; Lupia and McCubbins 1998).

This dynamic should be at work when someone who had publicly announced one stance rejects it in favor of a competing one. Costs are incurred because the acknowledgement that a previously held position was incorrect may carry social stigma and perhaps result in the cut-off of access to resources or compensation from those with whom the speaker had once been aligned. There is also general social reluctance to admit mistakes (Breines and Chen, 2013). Importantly, 
though, a conversion message entails more than just a source making a costly statement. A politician may engage in costly talk that denigrates a policy of his or her own party, without taking or defending a counter position, or without ever endorsing the policy in the first place. By contrast, a conversion message includes and justifies the arc of an individual's opinion change.

Dutton (1973) did undertake a study of "convert communicators." Because the "maverick" speakers in his experiment had abandoned a comfortable position to stake a new one - apparently guided by principle over payoff - they were seen as more trustworthy and elicited more opinion change than were those delivering the party line of their organization. Levine and Valle (1975) similarly found in the context of anti-alcohol communication that a reformed alcoholic was evaluated more favorably as a communicator than was "a life-long teetotaller."

H1a. Conversion message effects on attitudes will be mediated by perceived credibility of the speaker.

Recent research more directly tests the supposition that such messages work through the motivation the audience perceives to have guided the speaker. Proposing a "contradiction effect," Reich and Tormala (2013) argue that unexpected contradictions of one's former stance can prompt attributional reasoning - the process by which individuals attempt to explain the causes of behavior and events - to determine the source of the shift. If positive attributions (e.g., new information has been gathered, greater thought has been accorded to the subject), then the appeal will be more persuasive. We test this as a potential alternative - though highly related - way perceptions of the speaker might account for a conversion message's persuasive effects.

H1b. Conversion message effects on attitudes will be mediated by attributions of the speaker's motivation for opinion change.

\section{Enhanced argument strength}

We also explore an alternate hypothesis: Conversion messages work not through altering perception of the source, but by increasing the perceived quality of the message. In other words, conversion communication will be seen as making stronger arguments than messages that include 
the same facts, but lack the conversion arc. We test this with three messages: a one-sided advocacy message, a two-sided message in which the conversion is mentioned, and a two-sided message in which the conversion process is recounted in detail.

There is substantial evidence that thoughtfully processed, strong arguments are more persuasive than weak ones (Johnson, Smith-McLallen, Killeya-Jones, and Levin, 2004; Johnson and Eagly, 1989; Wood and Quinn, 2003). Typically, researchers employ a cognitive approach to argument strength, focusing on audience perception. In this tradition, perceived argument strength is defined as the audience member's perception of an argument's quality, strength, and persuasiveness (Zhao et al., 2011). This perceptual variable has been shown to be a strong and reliable predictor of attitude change (Dillard, Weber, and Vail, 2007).

There are a number of reasons conversion messages should be perceived as particularly strong arguments. Because they include references to a speaker's prior position as well as her current, contradictory stance, they are a type of refutational two-sided message. Refutational twosided messages, in which a speaker introduces criticisms against his or her stance in order to rebut them, increase perceived argument strength, reduce counter-arguing, and increase persuasiveness relative to one-sided messages (Allen, 1991; Hale, Mongeau, and Thomas, 1991; McGuire, 1985; O’Keefe, 1999).

Moreover, messages that detail the process of conversion should be seen as especially strong arguments. As Djupe and Gwiasda (2010) point out, audiences are likely to consider not only the source, but the process by which the source arrived at their decision. Conversion messages that include "the consideration of a decision-making process," (Djupe and Gwiasda, 2010: 75) may be seen as stronger arguments for this reason. Although understudied in persuasion research, the importance of process information is central in deliberative theory, where "the offering of reasons for political choice is the central act of public deliberation," (Ettema, 2007: 143), and in procedural justice, where public perceptions of legitimacy hinge on perceptions of fair process (Gibson et al., 
2003).

Why might conversion message effects work through perceptions of argument strength rather than speaker credibility? The unexpected incongruence of speaker and message (i.e., a proGM stance from a previously opposed environmentalist) in conversion messages may reduce reliance on peripheral cues - such as speaker characteristics - and enhance systematic thinking and scrutiny of argument strength (Maheswaran and Chaiken, 1991). This should allow for persuasion among both in- and out-group members (Djupe and Gwiasda, 2010). Since the conversion message will be dissonant and novel to in-group members (i.e., environmentalists), they may be less likely to rely on heuristics, and instead look to the decision-making process to judge the argument. If this process is consistent with group identity (i.e., using their acceptance of the science of climate change as a model to reconsider evidence about GM food safety), they should be more likely to update their attitudes accordingly. Moreover, process cues provide a signal to out-group members that arguments are considered, plausible, and well-founded.

H2. Conversion message effects on attitudes will be mediated by perceived argument strength.

\section{The GM Context}

We examine conversion message effects in the context of attitudes toward genetically modified crops. Genetically modified crops have been engineered by humans to express, or suppress, a specific genetic trait by altering some aspect of an organism's DNA (National Academies of Science, 2016). GM crops, such as corn and soy, are used widely in consumer food products in the United States. Because levels of Americans' knowledge about GM crops tend to be low, but people tend to be wary of them, genetic modification is a suitable topic for conversion messaging. Only 43\% of Americans know that GM crops are available for human consumption, and only a quarter (26\%) believe they have eaten food that has been genetically modified (Hallman, Cuite, and Morin, 2016). About 71\% of Americans say that they have heard little or nothing about 
GM foods, but about 39\% believe that GM foods present a risk to human health (Funk and Kennedy, 2016).

In a review of the scientific evidence, the National Academies of Science concluded that GM crops are as safe as conventionally grown crops (National Academies of Science, 2016). Despite this, the difference in opinion between scientists and the public on the safety of GM foods is larger than on controversial issues such as climate change, vaccines, and evolution (Funk and Rainie, 2015). That said, it is important to note that public skepticism toward GM crops is not in itself irrational. Little direct knowledge of the subject means individuals' views are instead informed by similar cases (Marris, 2001), an informational shortcut that conserves cognitive resources. Further, while reviews of research on GM crops' effects on environment and health tend to find little evidence of negative effects (e.g., Brookes and Barfoot, 2017; Nicolia et al., 2014; Panchin and Tuzhikov, 2017), research is ongoing, and the public may take such ongoing debate as a cue of uncertainty (Dixon and Clarke, 2013). Moreover, some scientific studies — while controversial, or even retracted within the scientific community (Wallace, 2014) — have indeed reported negative effects of GM products. Public views may incorporate some of this evidence as a credible basis in forming an opinion.

Importantly though, unlike some other scientific issues, such as evolution or climate change, attitudes about GM foods do not seem to be related to political ideology or religious beliefs in the American context. Democrats and Republicans are equally likely to find GM foods unsafe to eat, and panel survey data show political ideology does not predict attitudes about GM foods (Funk and Kennedy, 2016; author removed for blind review). Religious beliefs also often divide attitudes about similar science issues such as stem-cell research and synthetic biology (e.g., Ho, Brossard, and Scheufele, 2008), but there is no evidence of religious belief influencing attitudes about GM foods (author removed for blind review). In sum, knowledge levels about GM foods are low, but there are strong perceptions of risk not associated with political or religious beliefs. In such 
conditions, messages that acknowledge concerns while offering explanations to counter them may be particularly conducive to attitude change. In this case, conversion messages may be able to persuade individuals to hold attitudes more consistent with scientific consensus.

\section{Methods}

\section{Sample}

Data were collected by Research Now from March 28, 2017 to April 5, 2017. U.S. adults 18 years or older $(\mathrm{N}=727)$ participated in the experiment hosted on Qualtrics. This sample excludes respondents who took more than 1 hour to complete the survey $(n=75)$. Participants completed the experiment in a median time of 14.10 minutes $(M=15.95$ minutes, $\mathrm{SD}=8.47) .{ }^{5}$ Participants were $55.2 \%$ female and $81.7 \%$ white, with a mean age of $45.66, \mathrm{SD}=15.81$, a median education of a bachelor's degree, and median household income of \$75-100,000. Respondents had a mean of .40 $(\mathrm{SD}=.85)$ children under 18

Party affiliation was measured with a 7-pt. item ranging from Strong Democrat (1) to Strong Republican (7) $(\mathrm{M}=3.86, \mathrm{SD}=1.96)$. Ideology ranged from Very Liberal (1) to Very Conservative (5) $(\mathrm{M}=3.00, \mathrm{SD}=1.13)$, and was computed by taking the average of social $(2.99, \mathrm{SD}=1.43)$ and economic $(\mathrm{M}=3.35, \mathrm{SD}=1.31)$ subscales $\left(\right.$ Cronbach's $\left.\alpha=.85^{6}\right)$. Mean religiosity was $2.20(\mathrm{SD}=$ 1.30) on a 5-pt. scale of religious service attendance, ranging from never (1) to more than once a week (5).

\section{Design}

\footnotetext{
${ }^{5}$ The fastest $5 \%(n=39)$ completed the experiment in 6.59 minutes or less. However, we did not attempt to identify and drop speeders due to, e.g., Greszki et al. (2015): "speeding primarily adds some random noise to the data and attenuates correlations, if it makes a difference at all."

${ }^{6}$ Chronbach's alpha is a measure of internal consistency. A value of .7 is often regarded as acceptable, but the value is dependent on the number of items in the scale such that fewer items may yield lower values (Tavakol \& Dennick, 2011).
} 
The experiment consisted of three conditions designed using video excerpts from a talk given by Mark Lynas at the 2013 Oxford Farming Conference. ${ }^{7}$ The first condition included a title page with his picture and note reading "Mark Lynas, author of High Tide: How the climate crises is engulfing our planet, and Six Degrees: Our future on a hotter planet, explains why he's in favor of GMOs," followed by footage of Mark Lynas explaining the benefits of GM crops: that they require less insecticide; that billions of dollars of benefits are accruing to farmers in developing countries; that eager farmers have pirated them into India and Brazil; and that the technology is safer and more precise than conventional methods.

The second condition included a title page with his picture and note reading, "Mark Lynas, author of High Tide: How the climate crises is engulfing our planet, and Six Degrees: Our future on a hotter planet, on changing his mind about GMOs," followed by footage of Mark Lynas explaining a shift in his beliefs about GM crops. He discusses his prior beliefs about GM crops (that they increase the use of chemicals; that they benefit only big companies; that they are unwanted in developing countries; and that the technology is dangerous) and, having realized that these were "myths," his current beliefs (that they require less insecticide; that billions of dollars of benefits are accruing to farmers in developing countries; that eager farmers have pirated them into India and Brazil; and that the technology is safer and more precise than conventional methods).

The third condition included a title page with his picture and a note reading, "Mark Lynas, author of High Tide: How the climate crises is engulfing our planet, and Six Degrees: Our future on a hotter planet, explains why he changed his mind about GMOs," followed by footage of Mark Lynas explaining what he used to think about GM crops, what he thinks of them now, and how he changed his mind about them. This condition included the footage from condition two, but also included footage in which Lynas details his realization that the anti-GM movement he helped lead

\footnotetext{
${ }^{7}$ Based on a desire to employ externally valid stimuli, we focus on Lynas, a unique figure in his public conversion from anti- to pro-GMO environmentalism. We explore this trade-off further in the discussion section.
} 
was a form of anti-science environmentalism, which was inconsistent with his pro-science environmentalism and advocacy regarding climate change. Realizing this contradiction prompted additional reading of the scientific literature, through which Lynas shifted his beliefs.

Condition 1, the advocacy message, was 1:30 in length. Condition 2 was 1:23 and Condition 3 was 3:15. This design allows us to test advocacy against conversion at equivalent length (1 and 2). As we are also interested in the potential effect of decision making process information, we allowed Condition 3 to be longer. To maintain the equivalence of 1 and 2, and to avoid introducing additional confounding content to these conditions, we chose not balance length across all three.

Following the stimulus, participants were asked whether the speaker changed his mind about GMOs $(1=$ Yes $)$ - which he did in Conversion conditions (2 and 3$)$ but not the Advocacy condition (1). Conducted with ANOVA, the manipulation check showed that the conditions significantly differed $\left(F(2,773)=92.49, \eta_{\mathrm{p}}^{2}=.193, \mathrm{p}<.001\right)$. Post-hoc analysis using Tukey’s HSD indicated that those who saw a conversion message -- both condition $2(\mathrm{M}=.92, \mathrm{SD}=.27)$ and condition 3 $(\mathrm{M}=.91, \mathrm{SD}=.28)$-- were more likely to say the speaker changed his mind than those in the onesided advocacy condition $(\mathrm{M}=.54, \mathrm{SD}=.50$, both $\mathrm{p}<.001)$. The dependent variables were measured next followed by the mediator variables. A summary of all items can be found in Table 1.

\section{Dependent Variable}

Attitudes, behaviors, and policy support were measured as the dependent variable. These items were coded such that attitudes and behaviors favorable to GM foods (the argument made in the stimulus) were coded high. Behavioral and policy support outcomes were measured on $7 \mathrm{pt}$. scales ranging from Strongly Disagree (1) to Strongly Agree (7). These included "I would be comfortable eating genetically modified crops," $(\mathrm{M}=4.24, \mathrm{SD}=1.82)$, "I would support mandatory labeling of foods that have been genetically modified," (reverse coded, i.e., opposition to labelling) $(\mathrm{M}=2.48, \mathrm{SD}=1.47)$, and "I would support a ban on growing genetically modified crops," (reverse coded, i.e., opposition to ban) $(\mathrm{M}=4.26, \mathrm{SD}=1.75)$ (Runge et al., 2017; Yue et al., 2015). 
We also used 5 pt. scales ranging from Not at all Confident (1) to Extremely Confident (5) measuring whether respondents were confident that scientists were confident that "that genetically modified foods are as safe as conventional foods" $(\mathrm{M}=3.39, \mathrm{SD}=1.19)$, and whether the respondent was confident that "genetically modified foods are as safe as conventional foods" $(\mathrm{M}=$ $2.80, \mathrm{SD}=1.36)($ Corbett and Durfee, 2004). These five items had a high level of internal consistency (Cronbach's $\alpha=0.82$ ); for the main effect analyses, these five items were standardized and used to create a mean scale of $\mathrm{GM}$ attitude $(\mathrm{M}=0.01, \mathrm{SD}=0.75)$ in order to reduce measurement error and improve power (Ansolabehere, Rodden and Snyder 2008). ${ }^{8}$

\section{Mediators}

Perceived credibility $(M=4.65, S D=1.15)$ was measured using a 7-pt scale with 6 items, addressing the speaker's sincerity, honesty, trustworthiness, reliability, accuracy, and expertise (Cronbach's $\alpha=.95)$.

Attribution $(\mathrm{M}=4.83, \mathrm{SD}=1.20)$ was measured using a 7-pt scale with 3 items adapted from Reich and Tormala (2013) (Cronbach's $\alpha=.63)$ : "How likely is it that the speaker gathered new information about genetically modified organisms before giving his final opinion?”; “How thoughtful do you think the speaker is?"; and "How likely is it that the speaker's final opinion on genetically modified crops was the result of manipulation by others?” (reverse coded).

Perceived argument strength $(\mathrm{M}=4.37, \mathrm{SD}=0.99)$ was measured on a 7-pt. scale. The final measure consisted of the average of perceived argument strength across the four arguments (Cronbach's $\alpha=.93)$ made in the stimulus. These included that GM crops benefit insects $(\mathrm{M}=4.54$, $\mathrm{SD}=1.08)$, that they benefit farmers $(\mathrm{M}=4.45, \mathrm{SD}=1.08)$, that farmers are eager to use them $(\mathrm{M}$ $=4.19, \mathrm{SD}=1.04)$, and that they are safer than other conventional forms of breeding $(\mathrm{M}=4.30, \mathrm{SD}$ $=1.17)$. Each of these individual argument strength measures was the average of 6 items adapted

\footnotetext{
${ }^{8}$ We employed 5- and 7-pt. Likert scales based on the original use in the literature for each measure. However, in creating our composite dependent variable, we then used standardized z-scores to account for the difference.
} 
from Zhao et al (2011). The Cronbach's $\alpha$ of individual argument strength items ranged from .84 to .88.

[Table 1 here]

Random assignment was checked using analysis of variance. Conditions did not differ by any demographic (including gender, race, Hispanic origin, education, income, ideology, religiosity, and children under 18) with the exception of age and political party affiliation, both of which are controlled for in all analyses.

\section{Results}

Because we ask questions about the mechanism of conversion message effects rather than simply whether an effect exists, we therefore explore mediation - the process through which one variable exerts effects on another through one or more mediator variables (Preacher and Hayes, 2008). Bootstrapping, a data-resampling procedure used to produce confidence intervals for an indirect effect, is generally seen as a better method for estimating mediation hypotheses than older alternatives such as the Sobel test, as it can allow for confidence intervals that are asymmetric (MacKinnon et al., 2004; Preacher and Hayes, 2008). Therefore, bootstrapped 95\% confidence intervals employing 5,000 samples were calculated to test our mediation hypotheses. These statistical analyses were conducted with the PROCESS macro (Hayes, 2013, Model 4), which used ordinary least squares regression to estimate the direct and indirect effects of experimental conditions on attitudes about GM foods. PROCESS can simultaneously test the effects of two mediators, and their following effects on the dependent variable.

The competing hypotheses examine the mediating effects of views of the speaker and argument strength between the experimental conditions and attitudes about GM foods. The experimental conditions were first dummy-coded with the non-conversion message as the reference category before being entered as the independent variable, and the model also controlled for age, gender, race, education, children under 18, income, political party and political ideology. We 
include a number of covariates to adjust for variables expected to relate to GM attitudes, as covariate adjustment reduces biasedness of effect size estimation (Lin, 2013; Lee, 2016). Models without covariate adjustment (controlling only for party and age, as per the random assignment check) are substantively identical and are included in the appendix. The complete results are shown in Table 2 (comparing credibility and argument strength) and Table 3 (comparing attribution and argument strength).

[Table 2 here]

When looking at perceived credibility (H1a), the mediation was not significant. There was no direct effect of conversion without explanation $(b=.02, p=.88)$, and no direct effect of conversion with explanation on attitudes about GM foods $(b=.13, p=.26)$. There was no indirect effect through perceived credibility for either the conversion without explanation condition (pointestimate $=0.01(0.01), 95 \%$ CI $[-0.0111,0.0153]$ or the conversion with explanation condition (point-estimate $=0.01(0.01), 95 \%$ CI $[0.0023,0.0234])$. H1a was rejected.

Replacing perceived credibility with attribution of the speaker's motivation (H1b) produced similar results. There was no indirect effect through attribution for either the conversion without explanation condition (point-estimate $=0.00(0.00), 95 \%$ CI $[-0.0134,0.0042])$ or the conversion with explanation condition (point-estimate $=0.00(0.00), 95 \% \mathrm{CI}[-0.0025,0.0091]) . \mathrm{H} 1 \mathrm{~b}$ was rejected.

\section{[Table 3 here]}

However, when looking at argument strength (H2), the mediation was supported. ${ }^{9}$ Both the conversion without explanation condition $(b=.28, p<0.01)$, and the conversion with explanation ( $b=.28, p<0.01)$, significantly increased the perceived argument strength. The results indicate that the conversion without explanation had a positive indirect effect on perceived argument strength

\footnotetext{
${ }^{9}$ For clarity and space, we refer here to the results of the model including credibility. The results of the model including attribution in the place of credibility are substantively identical, as reported in Table 3 .
} 
(point estimate $=0.15(0.05), 95 \%$ CI $[0.0375,0.2554])$, as did the conversion with explanation condition (point estimate $=0.15(0.05), 95 \%$ CI $[0.0436,0.2501]) . \mathrm{H} 2$ was supported. Figure 1 depicts these results. In sum, conversion messages can influence attitudes about GM foods through perceived argument strength, but not perceived credibility of the speaker.

[Figure 1 here]

Finally, we considered the possibility of conditional effects on the relationship between the experimental conditions and the mediators. We tested the effects of climate change belief, environmentalism, and deference to science separately as moderators of the previous mediation models. Results indicate that the moderated mediation models were not significant. Deference to science directly influenced both perceived credibility and argument strength but did not moderate the effect of any treatment condition on the mediating variables. Climate belief did moderate the effect of the conversion without explanation treatment on credibility, but the model was not significant. Climate belief had no other effects. Environmentalism moderated the effect of the conversion with explanation treatment on perceived credibility, but the model was not significant. In other words, the mediational pathway of conversion message effects on attitudes by way of perceived argument strength was not conditional on key markers of environmental group affiliation. Full results of the moderated mediations can be found in Tables A1-A6 in Appendix A.

\section{Discussion}

Conversion messages appear to be a common rhetorical device used by individuals and organisations to overcome the influence of group affiliations on attitudes toward contested scientific issues (The Guardian, 2018; Madrigal, 2007; Pomeroy, 2018; Schellenberger, 2017; Storr, 2013; Voices for Vaccines, n.d), in part because they highlight how an opposing position is actually aligned with the convert's group's true values. However, little research has examined the effectiveness of this technique, nor do we understand the mechanisms through which it might influence attitudes. In this study, we show that the GM conversion messages by a formerly anti-GM 
environmentalist, Mark Lynas, influenced attitudes toward GM foods via increased perception of argument strength and not enhanced speaker credibility. Because conversion messages' effects stem from enhanced perceptions of argument quality, strength, and persuasiveness (rather than a heuristic judgement of the speaker), they are more likely to have been processed centrally, leading to more durable and persistent attitude changes (Greenwald and Leavitt, 1984; Petty and Cacioppo, 1986, Zhao et al., 2011).

The study showed that when compared to a one-sided advocacy message, the refutational two-sided conversion messages, through their perceived argument strength, were more effective at influencing attitudes about GM foods (Allen, 1991; Hale, Mongeau, and Thomas, 1991; McGuire, 1985; O'Keefe, 1999), but found no evidence for credibility as a mediator on GM attitudes (contrary to Dutton, 1973). This finding supports the notion that the unexpected shift in the position of the speaker - who previously held an anti-GM stance, but after revision now holds a pro-GM position - prompted central or systematic processing of the argument (Djupe and Gwiasda, 2010; Maheswaran and Chaiken, 1991; Petty and Cacioppo, 1986).

The mediating role of argument strength may stem from the inherent nature of the conversion message - requiring scrutiny, which in turn reveals justified arguments (in comparison to a one-sided advocacy message). In this way, conversion messages may serve as an exemplar of the deliberative process, with a single source. Moreover, our results suggest the conversion message structure can be broadly effective, and not necessarily conditional on audience members' identity or attitudes, at least in similar lower-salience contexts.

It is also worth noting that we find no difference between a basic conversion message and one including more elaborate information about how the conversion conforms with in-group norms. A more parsimonious conversion message appears to work as well as a more elaborate version. Said another way, conversion messages were more effective than advocacy whether equivalent in length (Condition 2), or longer (Condition 3). Moreover, we see no differential effectiveness between 
conversion messages, despite the length difference. It appears unlikely length played any role in our observations.

In an environment in which attitudes toward contested science are often driven by group affiliation and associated value conflicts, these findings point the way toward an effective researchinformed communication strategy (Hornsey and Fielding, 2017). By the same token, however, they also suggest the potential for conversion messages that intentionally undermine public understanding of scientific issues (e.g., McCright and Dunlap, 2017).

Although our results are based on a well-powered national sample of U.S. adults, there are limitations to this study. First, the findings may not extend beyond the American context. Our sample includes a number of individuals who do not have strong pro- or anti-GM attitudes. ${ }^{10}$ While this represents most U.S. adults' attitudes toward GM foods (Funk and Kennedy, 2016), conversion message effects, and mechanisms, should also be tested among those with strong pre-existing attitudes about GM foods. We also only examined conversion messages in the context of GM foods, where individuals generally have low levels of knowledge and familiarity with GM technology (Hallman, Hebden, Aquino, et al, 2004; Funk and Kennedy, 2016). Although a common limitation in communication experiments, relying on single message treatments leaves a possibility that any effects detected may be specific to the message topic or other characteristics (Jackson and Jacobs, 1983; Slater, Peter, and Valkenburg, 2015). Similarly, our decision to focus on a single direction of conversion -- from anti- to pro-GM -- warrants discussion. To be sure, future work should explore conversion messages dealing with different issues, and therefore potentially those of different direction. It is possible that narratives detailing shifts from favoring to opposing something, or from agreement with scientific consensus to against, might function differently than the message structure we examined. Finally, future work should also consider deep qualitative methods such as

\footnotetext{
${ }^{10} 18.6 \%$ of participants rated the issue of genetic modification as 'very' or 'extremely important.' Only $8.1 \%$ self-reported knowing 'a lot' or 'a great deal' about the issue.
} 
in-depth interviews or focus groups to better understand how the public makes sense of and are affected by these messages, which may extend beyond the models we test here.

Regardless, the persuasiveness of conversion messages has practical as well as theoretical implications. On the practical side, first-person delivery of two-sided messages that describe prior beliefs and explain current, more scientifically accurate ones may be useful in changing attitudes because they are perceived as inherently strong arguments. Although other topics should be tested and the longevity of the effect explored in future research, this study suggests that the intuition that conversion can help persuade vulnerable populations on scientifically aligned health practices (e.g., among vaccine hesitant populations) deserves greater attention.

Many groups attempt to influence public attitudes toward contested science, and do so by turning to a variety of arguments (Hornsey and Fielding, 2017). There is a great deal of research demonstrating that arguments perceived as strong are more persuasive (e.g., Petty and Brinol, 2010); however, there is less research on which particular rhetorical forms are perceived as strong arguments by general audiences (Hoeken and Hustinx, 2009; Slater and Rouner, 1996; Vancil 1993). Our study adds to the field's understanding by confirming conventional wisdom (Lazarsfeld, 1949; Watts, 2011) and demonstrating the existence of an effect of an important form of narrative, that recount one's conversion, at least in the context of attitudes about GM foods. Future research should test whether conversion messages about other issues related to health and science elicit attitudes more consistent with scientific consensus, and are able to influence political or scientific beliefs more broadly. 
Table 1. Summary of dependent variable and mediators

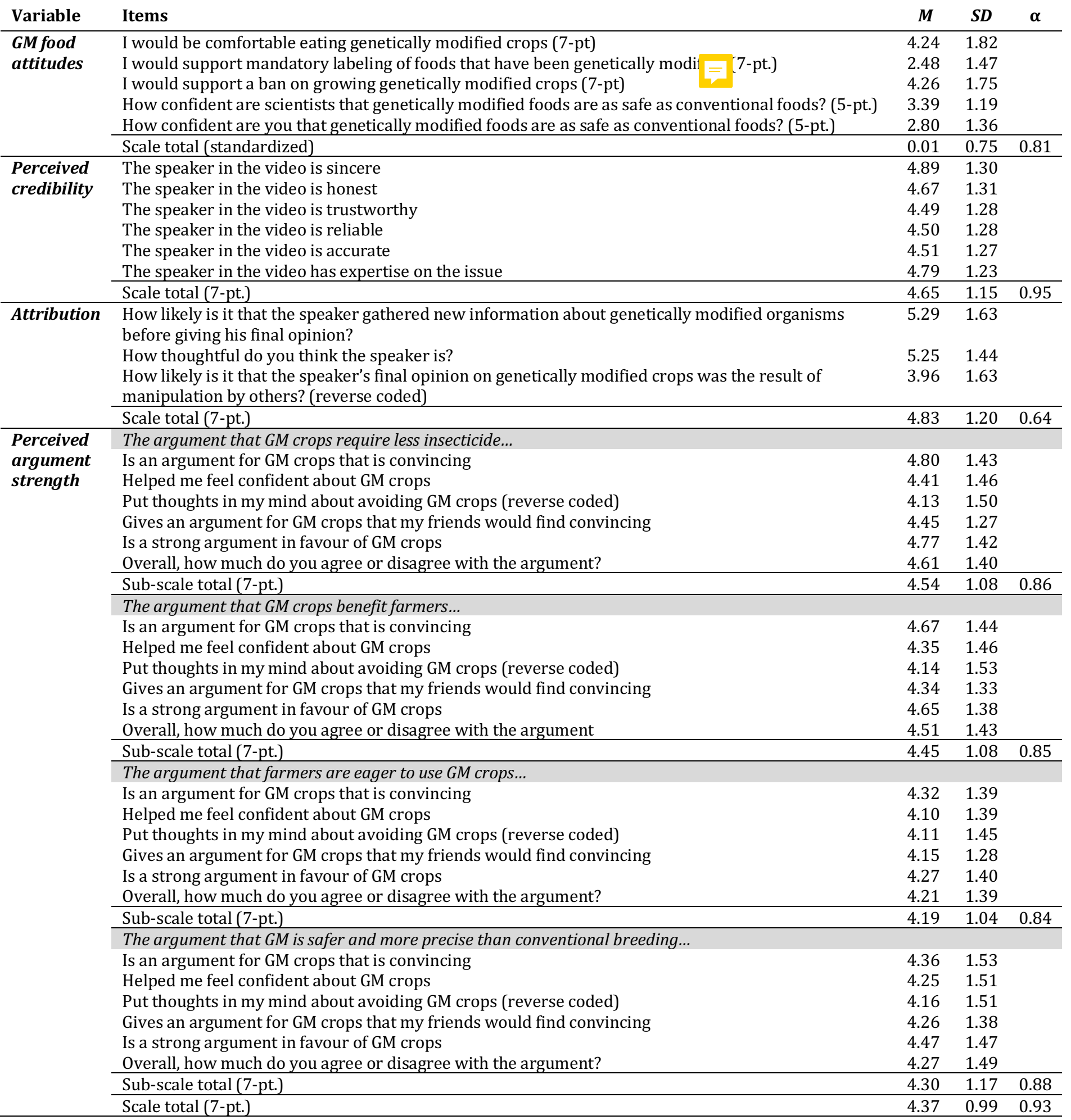


Table 2. Effect of experimental conditions on attitudes about GM safety mediated through perceived credibility and argument strength, controlling for age, gender, race, education, children under the age of 18, household income, political party, and political ideology

\begin{tabular}{|c|c|c|c|c|c|c|c|c|c|}
\hline \multirow[b]{3}{*}{ (Constant) } & \multicolumn{3}{|c|}{ Credibility } & \multicolumn{3}{|c|}{ Argument Strength } & \multicolumn{3}{|c|}{ GM Food Attitudes } \\
\hline & $b$ & $(\mathrm{SE})$ & & $b$ & (SE) & & $b$ & (SE) & \\
\hline & 4.332 & $(0.358)$ & $* * *$ & 3.996 & $(0.299)$ & $* * *$ & -2.143 & $(0.174)$ & $* * *$ \\
\hline Age & 0.000 & $(0.003)$ & & -0.002 & $(0.003)$ & & -0.004 & $(0.001)$ & $* *$ \\
\hline Gender & -0.134 & $(0.097)$ & & -0.116 & $(0.053)$ & & -0.096 & $(0.041)$ & $*$ \\
\hline Race & 0.367 & $(0.125)$ & $* *$ & 0.205 & $(0.104)$ & $*$ & 0.017 & $(0.053)$ & \\
\hline Education & 0.107 & $(0.030)$ & $* * *$ & 0.068 & $(0.025)$ & $* *$ & 0.026 & $(0.013)$ & $*$ \\
\hline Children under 18 & -0.001 & $(0.056)$ & & -0.086 & $(0.046)$ & & -0.033 & $(0.023)$ & \\
\hline Income & -0.042 & $(0.027)$ & & -0.014 & $(0.023)$ & & -0.016 & $(0.011)$ & \\
\hline Party & 0.049 & $(0.033)$ & & 0.031 & $(0.028)$ & & 0.013 & $(0.014)$ & \\
\hline Ideology & -0.142 & $(0.057)$ & $*$ & -0.048 & $(0.048)$ & & -0.037 & $(0.024)$ & \\
\hline $\begin{array}{l}\text { Conversion without } \\
\text { explanation }\end{array}$ & 0.018 & $(0.121)$ & & 0.276 & $(0.101)$ & $* *$ & -0.063 & $(0.051)$ & \\
\hline Conversion with explanation & 0.129 & $(0.114)$ & & 0.277 & $(0.095)$ & $* *$ & -0.024 & $(0.048)$ & \\
\hline Credibility & & & & & & & 0.046 & $(0.022)$ & $*$ \\
\hline Argument Strength & & & & & & & 0.530 & $(0.026)$ & $* * *$ \\
\hline
\end{tabular}

Note: $* p<0.05,{ }^{* *} p<0.01,{ }^{* * *} p<0.001 . N=597$ 
Table 3. Effect of experimental conditions on attitudes about GM safety mediated through attribution and argument strength, controlling for age, gender, race, education, children under the age of 18 , household income, political party, and political ideology

\begin{tabular}{|c|c|c|c|c|c|c|c|c|c|}
\hline \multirow[b]{3}{*}{ (Constant) } & \multicolumn{3}{|c|}{ Attribution } & \multicolumn{3}{|c|}{ Argument Strength } & \multicolumn{3}{|c|}{ GM Food Attitudes } \\
\hline & \multirow{2}{*}{$\begin{array}{l}b \\
4.220\end{array}$} & \multirow{2}{*}{$\begin{array}{l}(\mathrm{SE}) \\
(0.354)\end{array}$} & \multicolumn{2}{|r|}{$b$} & \multicolumn{2}{|l|}{$(\mathrm{SE})$} & $b$ & \multicolumn{2}{|l|}{$(\mathrm{SE})$} \\
\hline & & & $* * *$ & 3.986 & $(0.295)$ & $* * *$ & -2.145 & $(0.173)$ & $* * *$ \\
\hline Age & 0.010 & $(0.003)$ & $* *$ & -0.002 & $(0.003)$ & & -0.005 & $(0.001)$ & $* *$ \\
\hline Gender & .037 & $(0.097)$ & & -0.105 & $(0.080)$ & & -0.112 & $(0.040)$ & $* *$ \\
\hline Race & 0.376 & $(0.124)$ & $* *$ & 0.203 & $(0.104)$ & $*$ & 0.005 & $(0.052)$ & \\
\hline Education & 0.089 & $(0.030)$ & $* *$ & 0.066 & $(0.025)$ & $* *$ & 0.026 & $(0.013)$ & $*$ \\
\hline Children under 18 & -0.082 & $(0.056)$ & & -0.081 & $(0.046)$ & & -0.031 & $(0.023)$ & \\
\hline Income & -0.049 & $(0.027)$ & & -0.013 & $(0.022)$ & & -0.015 & $(0.011)$ & \\
\hline Party & -0.003 & $(0.033)$ & & 0.030 & $(0.028)$ & & 0.014 & $(0.014)$ & \\
\hline Ideology & -0.128 & $(0.057)$ & $*$ & -0.047 & $(0.048)$ & & -0.040 & $(0.024)$ & \\
\hline $\begin{array}{l}\text { Conversion without } \\
\text { explanation }\end{array}$ & -0.043 & $(0.060)$ & & 0.146 & $(0.050)$ & $* *$ & -0.034 & $(0.026)$ & \\
\hline Conversion with explanation & 0.031 & $(0.038)$ & & 0.093 & $(0.032)$ & $*$ & -0.010 & $(0.016)$ & \\
\hline Attribution & & & & & & & 0.067 & $(0.020)$ & $* *$ \\
\hline Argument Strength & & & & & & & 0.521 & $(0.024)$ & $* * *$ \\
\hline
\end{tabular}

Note: $* p<0.05, * * p<0.01,{ }^{* * *} p<0.001 . N=597$ 
Figure 1. Indirect Effect of Conversion Messages on Attitudes about GM Foods

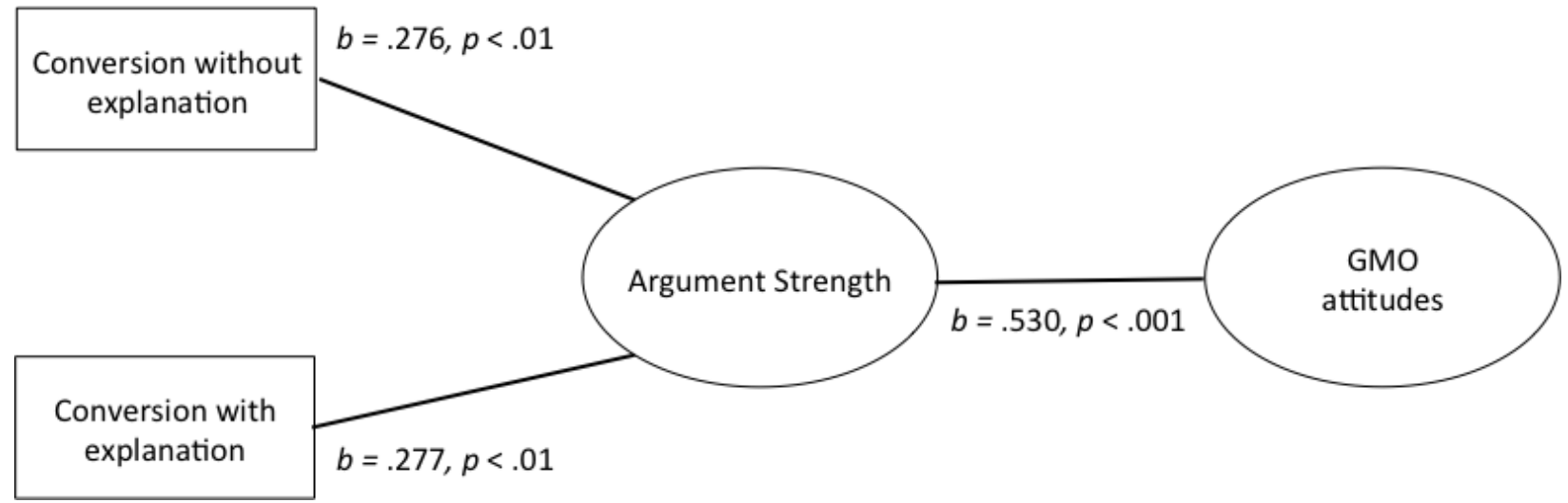

Note: Indirect effects based on 5,000 bootstrap samples with bias corrected confidence intervals. Indirect effect of conversion without explanation through argument strength $=.15(.05)(95 \% \mathrm{CI}$ $[0.0436,0.2524])$. Indirect effect of conversion with explanation through argument strength $=.15$ (.05) $(95 \%$ CI $[0.0421,0.2472]) . N=597$. 


\section{References}

Allen M (1991) Meta-analysis comparing the persuasiveness of one- sided and two- sided messages. Western Journal of Speech Communication, 55: 390-404. doi: $\underline{10.1080 / 10570319109374395}$

Anderson AA, Scheufele DA, Brossard D, and Corley EA (2011) The role of media and deference to scientific authority in cultivating trust in sources of information about emerging technologies. International Journal of Public Opinion Research, 24: 225-237. doi: $\underline{10.1093 / \text { ijpor/edr032 }}$

Ansolabehere S, Rodden J, and Snyder JM (2008) The strength of issues: Using multiple measures to gauge preference stability, ideological constraint, and issue voting. American Political Science Review, 102: 215-232.

Bauer M (2009) The evolution of public understanding of science-discourse and comparative evidence. Science, Technology and Society, 14: 221-240.

Bell C (2017) General election 2017: Why I switched from Tories to Labour. BBC, June 10. Available at: http://www.bbc.co.uk/news/election-2017-40216240 (accessed 09 October 2017).

Berinsky AJ (2015) Rumors and health care reform: experiments in political misinformation. British Journal of Political Science, 1-22. doi: 10.1017/S0007123415000186

Booth WC (1995) The Rhetoric of Fundamentalist Conversion Narratives. In: Marty ME and Appleby RS (eds) Fundamentalisms Comprehended. Chicago: University of Chicago Press: pp. $367-395$.

Bord RJ, Fisher A and O'Connor RE (1998) Public perceptions of global warming: United States and international perspectives. Climate Research, 11: 75-84. 
Breines JG and Chen S (2013) Activating the inner caregiver: The role of support-giving schemas in increasing state self-compassion. Journal of Experimental Social Psychology, 49: 58-64. doi: 10.1016/j.jesp.2012.07.015

Brookes G and Barfoot P (2017) Environmental impacts of genetically modified (GM) crop use 1996-2015: impacts on pesticide use and carbon emissions. GM Crops \& Food, 8: 117-147.

Brossard D and Nisbet MC (2007) Deference to scientific authority among a low information public: Understanding US opinion on agricultural biotechnology. International Journal of Public Opinion Research, 19: 24-52. doi: 10.1093/ijpor/ed1003

Cacciatore M, Browning, N, Scheufele DA, Brossard D, Xenos MA and Corley EA (2016) Opposing ends of the spectrum: Exploring trust in scientific and religious authorities. Public Understanding of Science: 1-18. doi: 10.1177/0963662516661090.

Caldwell P (1983) The Puritan conversion narrative: The beginnings of American expression. Cambridge University Press.

Campbell A, Converse PE, Miller WE and Stokes DE (1960) The American Voter. New York: John Wiley.

Carlyle D (2017) How I Saw the Light About Race. American Renaissance, March 17. Available at: https://www.amren.com/features/2017/03/how-i-saw-the-light-race-red-pill/ (accessed 09 October, 2017.

Corbett, JB and Durfee JL (2004) Testing public (un)certainty of science: Media representations of global warming. Science Communication, 26: 129. doi:10.1177/1075547004270234

Dillard JP, Weber KM and Vail RG (2007) The relationship between the perceived and actual effectiveness of persuasive messages: A meta- analysis with implications for formative campaign research. Journal of Communication, 57: 613-631. doi: 10.1111/j.1460$\underline{2466.2007 .00360 . x}$ 
Dixon GN and Clarke CE (2013) Heightening uncertainty around certain science: Media coverage, false balance, and the autism-vaccine controversy. Science Communication, 35: 358-382.

Djupe PA and Gwiasda GW (2010) Evangelizing the environment: Decision process effects in political persuasion. Journal for the Scientific Study of Religion, 49: 73-86. doi: 10.1111/j.1468-5906.2009.01493.x

Drummond C and Fischhoff B (2017) Individuals with greater science literacy and education have more polarized beliefs on controversial science topics. Proceedings of the National Academy of Sciences, 114: 9587-9592.

Dutton DG (1973) The maverick effect: Increased communicator credibility as a result of abandoning a career. Canadian Journal of Behavioural Science, 5: 145. doi:

$\underline{10.1037 / \mathrm{h} 0082339}$

Elleithee M (2013) To my daughter on Father's Day: Sorry I used to be a sexist. Salon, June 16. Available at: https://www.salon.com/2013/06/16/to_my_daughter_on_fathers_day_sorry_i_used to_be_a _sexist/(accessed 09 October, 2017).

Ettema JS (2007) Journalism as reason-giving: Deliberative democracy, institutional accountability, and the news media's mission. Political Communication, 24: 143-160. doi: $\underline{10.1080 / 10584600701312860}$

Fishbein M and Ajzen I (1981) Acceptance, yielding, and impact: Cognitive processes in persuasion. In: Petty RE, Ostrom T and Brock T (eds) Cognitive responses in persuasion. Hillsdale, NJ: Erlbaum: pp. 339-359.

Fredriksen P (1986) Paul and Augustine: Conversion narratives, orthodox traditions, and the retrospective self. The Journal of Theological Studies: 3-34. http://www.jstor.org/stable/23962967 
Funk C and Kennedy B (2016) The new food fights: U.S. public divides over food science. Pew Research Center. Available at: http://www.pewinternet.org/2016/12/01/public-opinionabout-genetically-modified-foods-and-trust-in-scientists-connected-with-these-foods/

Funk C and Rainie L (2015) Public and Scientists' views on science and society. Pew Research Center. Available at: http://www.pewinternet.org/2015/01/29/public-and-scientists-viewson-science-and-society/

Gibson JL, Caldeira GA and Spence LK (2003) The Supreme Court and the US presidential election of 2000: Wounds, self-inflicted or otherwise? British Journal of Political Science, 33: 535-556. doi: 10.1017/S0007123403000243

Greenwald AG and Leavitt C (1984) Audience involvement in advertising: Four levels. Journal of Consumer research, 11: 581-592. doi: 10.1086/208994

Greszki R, Meyer M and Schoen H (2015) Exploring the effects of removing "too fast" responses and respondents from web surveys. Public Opinion Quarterly, 79: 471-503.

Groeling T and Baum MA (2008) Crossing the water's edge: Elite rhetoric, media coverage, and the rally-round-the-flag phenomenon. The Journal of Politics, 70: 1065-1085. doi: $10.1017 / \mathrm{S} 0022381608081061$

The Guardian (2018) 'My partner convinced me of the facts': Readers on changing their opinion on climate change. The Guardian, May 14. Available at:

https://www.theguardian.com/environment/2018/may/14/my-partner-convinced-me-of-thefacts-readers-on-changing-their-opinion-on-climate-change

Hale JL, Mongeau PA and Thomas RM (1991) Cognitive processing of one- and two- sided persuasive messages. Western Journal of Speech Communication, 55: 380-389. doi: $\underline{10.1080 / 10570319109374394}$

Hallman WK, Cuite CL and Morin XK (2016) Public perceptions of animal-sourced genetically modified food products. Journal of Animal Science, 94(5): 216. doi:10.2527/jam2016-0452 
Hindmarsh DB (2005) The evangelical conversion narrative: Spiritual autobiography in early modern England. Oxford University Press on Demand.

Ho SS, Brossard D and Scheufele DA (2008) Effects of value predispositions, mass media use, and knowledge on public attitudes toward embryonic stem cell research. International Journal of Public Opinion Research, 20: 171-192. doi: 10.1093/ijpor/edn017

Hoeken H and Hustinx L (2009) When is statistical evidence superior to anecdotal evidence in supporting probability claims? The role of argument type. Human Communication Research, 35: 491-510. doi: 10.1111/j.1468-2958.2009.01360.x

Hornsey MJ and Fielding KS (2017) Attitude roots and Jiu Jitsu persuasion: Understanding and overcoming the motivated rejection of science. American Psychologist, 72: 459.

Jackson S and Jacobs S (1983) Generalizing about messages: Suggestions for design and analysis of experiments. Human Communication Research, 9: 169-191. doi: 10.1111/j.1468$\underline{2958.1983 . t b 00691 . x}$

Johnson BT and Eagly AH (1989) Effects of involvement on persuasion: A meta-analysis. Psychological bulletin, 106: 290.

Johnson BT, Maio GR and Smith-McLallen A (2005) Communication and attitude change: Causes, processes, and effects. In: Albarracin D, Johnson BT, and Zanna MP (eds) The handbook of attitudes. Mahwah, NJ: Erlbaum: pp. 617-669.

Johnson BT, Smith-McLallen A, Killeya LA and Levin KD (2004) Truth or Consequences:

Overcoming Resistance to Persuasion with Positive. Resistance and Persuasion: 215.

Jordan MD (1986) Ancient philosophic protreptic and the problem of persuasive genres. Rhetorica, 4: 309-333.

Kahan DM, Jenkins- Smith H and Braman D (2011) Cultural cognition of scientific consensus. Journal of Risk Research, 14: 147-174. 
Lazarsfeld PF (1949) The American soldier: An expository review. Public Opinion

Quarterly, 13(3): 377-404. doi: 10.1086/266089

Lee PH (2016) Covariate adjustments in randomized controlled trials increased study power and reduced biasedness of effect size estimation. Journal of clinical epidemiology, 76: 137-146. doi: $10.1016 /$ j.jclinepi.2016.02.004

Levine JM and Valle RS (1975) The convert as a credible communicator. Social Behavior and Personality: an international journal, 3: 81-90. doi: 10.2224/sbp.1975.3.1.81

Lin W (2013) Agnostic notes on regression adjustments to experimental data: Reexamining Freedman's critique. The Annals of Applied Statistics, 7: 295-318.

Longaker M (2012) Letters to Power: Public Advocacy Without Public Intellectuals. Philosophy \& Rhetoric, 45: 468-472.

Lupia A and McCubbins MD (1998) The democratic dilemma: Can citizens learn what they need to know?. Cambridge University Press.

Lyngar E (2014) I was poor, but a GOP die-hard: How I finally left the politics of shame. Salon, July 16. Available at:

https://www.salon.com/2014/07/16/i_was_poor_but_a_gop_die_hard_how_i_finally_left_th e politics_of_shame/ (accessed 09 October, 2017).

MacGillis A (2011) Conversion Narrative, Iowa Caucus Edition. The New Republic, December 28. Available at: https://newrepublic.com/article/98991/conversion-narrative-iowa-caucusedition (accessed 09 October, 2017).

Madrigal A (2007) Co-Founder of Greenpeace Envisions a Nuclear Future. Wired, Nov 19. Available at: https://www.wired.com/2007/11/co-founder-of-greenpeace-envisions-anuclear-future/ 
Maheswaran D and Chaiken S (1991) Promoting systematic processing in low-motivation settings: effect of incongruent information on processing and judgment. Journal of personality and social psychology, 61: 13.

Marris C (2001) Public views on GMOs: deconstructing the myths: Stakeholders in the GMO debate often describe public opinion as irrational. But do they really understand the public? EMBO Reports, 2: 545-548.

McCright AM and Dunlap RE (2017) Combatting misinformation requires recognizing its types and the factors that facilitate its spread and resonance. Journal of Applied Research in Memory and Cognition, 6: 389-396.

McGuire WJ (1985) Attitudes and attitude change. In: Lindzey G and Aronson E (eds) Handbook of social psychology (3rd ed., Vol. 2,). New York: Random House: pp. 233-346.

McGuire WJ (2000) Standing on the shoulders of ancients: Consumer research, persuasion, and figurative language. Journal of Consumer Research, 27: 109-114. doi: $10.1086 / 314312$

National Academies of Science (2016) Genetically engineered crops: Experiences and prospects. Washington, DC: The National Academies Press. doi:10.17226/23395

National Academies of Sciences, Engineering, and Medicine. (2017). Genetically engineered crops: experiences and prospects. Washington, DC: National Academies Press.

Nauroth P, Gollwitzer M, Kozuchowski H, Bender J and Rothmund T (2017) The effects of social identity threat and social identity affirmation on laypersons' perception of scientists. Public Understanding of Science, 26: 754-770.

Nicolia A, Manzo A, Veronesi F and Rosellini D (2014) An overview of the last 10 years of genetically engineered crop safety research. Critical Reviews in Biotechnology, 34: 77-88.

Nisbet EC, Cooper KE and Garrett RK (2015) The partisan brain: How dissonant science messages lead conservatives and liberals to (dis) trust science. The ANNALS of the American Academy of Political and Social Science, 658: 36-66. 
O'Connor RE, Bord RJ, Yarnal B and Wiefek N (2002) Who wants to reduce greenhouse gas emissions. Social Science Quarterly, 83: 1-17. doi: 10.1111/1540-6237.00067

O’Keefe DJ (1999) How to handle opposing arguments in persuasive messages: A meta-analytic review of the effects of one-sided and two-sided messages. Annals of the International Communication Association, 22: 209-249. doi: 10.1080/23808985.1999.11678963

O’Keefe DJ (2002) Persuasion, theory \& research (2nd ed.). Thousand Oaks, CA: Sage.

Panchin AY and Tuzhikov AI (2017) Published GMO studies find no evidence of harm when corrected for multiple comparisons. Critical Reviews in Biotechnology, 37: 213-217.

Pasek J (2017) It's not my consensus: Motivated reasoning and the sources of scientific illiteracy. Public Understanding of Science, Online First: 0963662517733681.

Petty RE and Brinol P (2010) Attitude change. In: Baumeister RF and Finkel EJ (eds) Advanced social psychology: The state of the science: pp. 217-259.

Petty RE and Cacioppo JT (1986) The elaboration likelihood model of persuasion. Advances in experimental social psychology, 19: 123-205.

Pew Research Center (2017) The partisan divide on political values grows even wider. Available at: http://assets.pewresearch.org/wp-content/uploads/sites/5/2017/10/05162647/10-05-2017Political-landscape-release.pdf

Pomeroy R (2018). Trump's NASA Chief Changed His Mind on Climate Change. He Is a Scientific Hero. Space.com, June 1. Available at: https://www.space.com/40857-trumps-nasa-chiefchanged-his-mind-on-climate-change-he-is-a-scientific-hero.html

Reich T and Tormala Z (2013) When contradictions foster persuasion: An attributional perspective. Journal of Experimental Social Psychology, 49: 426-439. doi: 10.1016/j.jesp.2013.01.004 
$\underline{\text { Reinemann C and Maurer M (2005) Unifying or polarizing? Short-term effects and postdebate }}$ consequences of different rhetorical strategies in televised debates. Journal of Communication, 55: 775-794.

Reynolds R and Reynolds JL (2002) Evidence. In: Dillard JP \& Pfau M (eds) The persuasion handbook. Thousand Oaks, CA: Sage, pp. 427-444.

Runge KK, Brossard D, Scheufele DA, Rose KM and Larson BJ (2017) Attitudes about food and food-related biotechnology. Public Opinion Quarterly, 81: 577-596.

Schellenberger M (2017) Why I changed my mind about nuclear power: Transcript of Michael Shellenberger's TEDx Berlin 2017. Available at: http://environmentalprogress.org/bignews/2017/11/21/why-i-changed-my-mind-about-nuclear-power-transcript-of-michaelshellenbergers-tedx-berlin-2017

Slater DM, Peter J and Valkenburg PM (2015) Message variability and heterogeneity: a core challenge for communication research. Annals of the International Communication Association, 39(1): 3-31. doi: $\underline{\text { 10.1080/23808985.2015.11679170 }}$

Slater MD and Rouner D (1996) Value-affirmative and value-protective processing of alcohol education messages that include statistical evidence or anecdotes. Communication Research, 23(2): 210-235. doi: 10.1177/009365096023002003

$\underline{\text { Smith VJ (2007) Aristotle's classical enthymeme and the visual argumentation of the twenty-first }}$ century. Argumentation and Advocacy, 43: 114-123.

Storr W (2013) Mark Lynas: Truth, treachery and GM food. The Guardian, March 9. Available at: https://www.theguardian.com/environment/2013/mar/09/mark-lynas-truth-treachery-gm Stromberg P (1993) Language and self-transformation: A study of the Christian conversion narrative (Vol. 5). Cambridge University Press.

Tavakol M and Dennick R (2011) Making sense of Cronbach's alpha. International Journal of Medical Education, 2: 53. 
Vancil D (1993) Rhetoric and argumentation. Boston: Allyn and Bacon.

Veenstra AS, Hossain MD and Lyons BA (2014) Partisan media and discussion as enhancers of the belief gap. Mass Communication and Society, 17: 874-897.

Veenstra AS, Lyons BA and Fowler-Dawson A (2016) Conservatism vs. conservationism: Differential influences of social identities on beliefs about fracking. Environmental Communication, 10: 322-336. doi: 10.1080/17524032.2015.1127851

$\underline{\text { Voices for Vaccines (n.d.) From anti-vax to pro-vax. Voices for Vaccines. Available at: }}$ https://www.voicesforvaccines.org/from-anti-vax-to-pro-vax/

Volle J (2010) The Campaign for President of the United States, 1964. In: The Political Legacies of Barry Goldwater and George McGovern. Palgrave Macmillan US, pp. 29-50.

Wallace AH (2014) Editor in Chief of Food and Chemical Toxicology answers questions on retraction. Food and chemical toxicology: an international journal published for the British Industrial Biological Research Association, 65: 394-395.

Watts D (2011) Everything Is Obvious: * Once You Know the Answer. Crown Business.

Wood W and Quinn JM (2003) Forewarned and forearmed? Two meta-analysis syntheses of forewarnings of influence appeals. Psychological Bulletin, 129: 119. doi: 10.1037/0033$\underline{2909.129 .1 .119}$

Yue C, Zhao S, Cummings C and Kuzma J (2015) Investigating factors influencing consumer willingness to buy GM food and nano-food. Journal of Nanoparticle Research, 17: 283.

Zarefsky D (1980) Lyndon Johnson redefines "equal opportunity:"; The beginnings of affirmative action. Communication Studies, 31: 85-94.

Zhao X, Strasser A, Cappella J, Lerman C and Fishbein M (2011) A measure of perceived argument strength: Reliability and validity. Communication methods and measures, 5: 48-75. doi: $\underline{10.1080 / 19312458.2010 .547822}$ 


\section{Appendix A \\ Moderated-Mediation Models}

The credibility-enhancing and argument strength-enhancing effects of conversion messages, particularly those that include information about a decision-making process that conforms to group norms, should be stronger among in-group members. In the context under examination, we employ environmentalism, climate change beliefs, and deference to science (Brossard and Nisbet, 2007) as measures of group identification.

Individuals who hold attitudes in line with the scientific consensus typically have high deference to scientific authority. Deference to scientific authority refers to a stable and long-term predisposition to believe that scientists know what is best for the public, that they perform research that benefits public, and that they should be an authority when it comes to decisions on scientific issues (Brossard and Nisbet, 2007). Those with high deference to scientific authority are more likely to trust scientists and their institutions (Anderson, Scheufele, Brossard, and Corley, 2011; Cacciatore, Browning, Scheufele, et al, 2016), and are also more likely to hold positive attitudes towards GM foods (Brossard and Nisbet, 2007). Considering this, it is possible that individuals with high deference to scientific authority are more likely to find the speaker credible and the argument about supporting GM foods convincing.

Opponents of GM foods have often included environmentalists who believe there are negative health and environmental consequences to adopting the technology. However, it has been found that individuals holding pro-environmental attitudes adopt behaviors and support policies that help mitigate environmental damage (Bord, Fisher, and O'Connor, 1998; O'Connor, Bord, Yarnal, and Wiefek, 2002). A message that discusses the environmental benefits of GM foods including the potential to reduce the effects of climate change on crop vulnerabilities (National Academies of Sciences, 2016) should persuade those with pro-environmental attitudes and with high concerns of climate change. It is reasonable that those with pro-environmental attitudes or those with high 
concern about climate change will more likely find the speaker more credible and the argument of supporting GM that addresses climate change to be convincing. Because of these potential conditional effects, we considered the following moderators in the mediation models.

Environmentalism $(\mathrm{M}=4.95, \mathrm{SD}=1.23)$ was measured on a 7-pt. scale, using 5 items (Cronbach's $\alpha=.87$ ). These items measured agreement with the following statements: "I consider myself an environmentalist," "I make a strong effort to recycle everything I possibly can," "I worry about the effects of environmental pollution on my health," "Our children's lives will be worse because of our current wasteful habits," and "I support environmental advocacy groups," (Veenstra et al., 2016).

Climate change belief $(\mathrm{M}=3.43, \mathrm{SD}=.80)$ was measured with a 4-pt. item, ranging from “Climate change is just not happening," to "We just don't know enough yet about whether it's happening," to "Climate change is mostly because of natural patterns in the Earth's environment," to "Climate change is mostly the result of human activity such as burning fossil fuels," (Pew Research Center, 2017).

Deference to science $(\mathrm{M}=4.41, \mathrm{SD}=1.18)$ was measured on a 7-pt. scale using 4 items (Cronbach's $\alpha=.80$ ) adapted from Brossard and Nisbet (2007). These items measured agreement with the following statements: "Scientists know best what is good for the public," "It is important for scientists to get research done even if they displease people by doing it," "Scientists should do what they think is best, even if they have to persuade people that it is right," and "Scientists should make the decisions about the type of scientific research on agricultural biotechnology."

Results indicate that the moderated mediation models were not significant. Deference to science directly influenced both perceived credibility and argument strength but did not moderate the effect of any condition on the mediating variables. Climate belief did moderate the effect of the conversion without explanation condition on credibility, but the model was not significant. Climate belief had no other effects. Environmentalism moderated the effect of the conversion with 
explanation condition on perceived credibility, but the model was not significant. Full results of the moderated mediations can be found in Tables A1-A6.

Table A1. Effect of conversion without explanation condition on attitudes about GM safety mediated through credibility and argument strength, moderated by deference to science, controlling for age, gender, race, education, children under the age of 18, household income, political party, and political ideology

\begin{tabular}{|c|c|c|c|c|c|c|c|c|c|}
\hline & \multicolumn{3}{|c|}{ Credibility } & \multicolumn{3}{|c|}{ Argument Strength } & \multicolumn{3}{|c|}{ GMO Attitudes } \\
\hline & B & $(\mathrm{SE})$ & & $\mathrm{B}$ & $(\mathrm{SE})$ & & B & $(\mathrm{SE})$ & \\
\hline (Constant) & 1.888 & $(0.393)$ & $\begin{array}{l}* * \\
*\end{array}$ & 2.195 & $(0.335)$ & $\begin{array}{l}* * \\
* *\end{array}$ & -2.156 & $(0.175)$ & $\begin{array}{l}* * \\
* *\end{array}$ \\
\hline Age & 0.005 & $(0.003)$ & & 0.003 & $(0.075)$ & & -0.004 & $(0.001)$ & $* *$ \\
\hline Gender & -0.073 & $(0.087)$ & & -0.077 & $(0.075)$ & & -0.094 & $(0.041)$ & $*$ \\
\hline Race & 0.391 & $(0.124)$ & $* *$ & 0.133 & $(0.096)$ & $* *$ & 0.021 & $(0.053)$ & \\
\hline Education & 0.073 & $(0.030)$ & $* *$ & 0.042 & $(0.023)$ & $* *$ & 0.025 & $(0.013)$ & $*$ \\
\hline Children under 18 & 0.003 & $(0.050)$ & & -0.053 & $(0.043)$ & & -0.035 & $(0.024)$ & \\
\hline Income & -0.047 & $(0.025)$ & & -0.021 & $(0.021)$ & & -0.016 & $(0.011)$ & \\
\hline Party & 0.049 & $(0.030)$ & & 0.038 & $(0.026)$ & & 0.012 & $(0.014)$ & \\
\hline Ideology & -0.034 & $(0.053)$ & & 0.036 & $(0.050)$ & & -0.035 & $(0.024)$ & \\
\hline $\begin{array}{l}\text { Conversion without } \\
\text { explanation }\end{array}$ & -0.164 & $(0.421)$ & & 0.079 & $(0.358)$ & & -0.061 & $(0.051)$ & \\
\hline Conversion with explanation & 0.090 & $(0.103)$ & & 0.226 & $(0.088)$ & $*$ & -0.021 & $(0.048)$ & \\
\hline Credibility & & & & & & & 0.041 & $(0.022)$ & $*$ \\
\hline Argument strength & & & & & & & 0.532 & $(0.027)$ & $\begin{array}{l}* * \\
*\end{array}$ \\
\hline Deference to science & 0.455 & $(0.037)$ & $*$ & 0.350 & $(0.039)$ & $\begin{array}{l}* * \\
*\end{array}$ & & & \\
\hline $\begin{array}{l}\text { Conversion without } \\
\text { explanation x Deference to } \\
\text { science }\end{array}$ & 0.037 & $(0.090)$ & & 0.037 & $(0.077)$ & & & & \\
\hline
\end{tabular}

Note: $* p<0.05, * * p<0.01,{ }^{* * *} p<0.001$, Indirect effects based on 5,000 bootstrap samples with bias corrected confidence intervals. Conditional indirect effect of conversion without explanation through credibility, moderated by deference to science $=.00(.01)(95 \%$ CI $[-0.0080,0.0148])$. Conditional indirect effect of conversion with explanation through argument strength, moderated by deference to science $=.02(.04)(95 \% \mathrm{CI}[-0.0686,0.1051]) . N=596$. 
Table A2. Effect of conversion with explanation condition on attitudes about GM safety mediated through credibility and argument strength, moderated by deference to science, controlling for age, gender, race, education, children under the age of 18 , household income, political party, and political ideology

\begin{tabular}{|c|c|c|c|c|c|c|c|c|c|}
\hline \multirow{3}{*}{ (Constant) } & \multicolumn{3}{|c|}{ Credibility } & \multicolumn{3}{|c|}{ Argument Strength } & \multicolumn{3}{|c|}{ GMO Attitudes } \\
\hline & $\mathrm{B}$ & $(\mathrm{SE})$ & & $\mathrm{B}$ & $(\mathrm{SE})$ & & $\mathrm{B}$ & $(\mathrm{SE})$ & \\
\hline & 1.639 & $(0.405)$ & $\begin{array}{l}* * \\
*\end{array}$ & 2.214 & $(0.346)$ & $\begin{array}{l}* * \\
*\end{array}$ & -2.156 & $(0.175)$ & $\begin{array}{l}* * \\
*\end{array}$ \\
\hline Age & 0.005 & $(0.003)$ & & 0.003 & $(0.003)$ & & -0.004 & $(0.001)$ & $* *$ \\
\hline Gender & -0.077 & $(0.087)$ & & -0.077 & $(0.075)$ & & -0.094 & $(0.041)$ & $*$ \\
\hline Race & 0.303 & $(0.027)$ & $* *$ & 0.133 & $(0.096)$ & & 0.021 & $(0.053)$ & \\
\hline Education & 0.074 & $(0.027)$ & $* *$ & 0.042 & $(0.023)$ & & 0.025 & $(0.013)$ & $*$ \\
\hline Children under 18 & 0.020 & $(0.050)$ & & -0.051 & $(0.043)$ & & -0.035 & $(0.024)$ & \\
\hline Income & -0.048 & $(0.024)$ & $*$ & -0.022 & $(0.021)$ & & -0.016 & $(0.011)$ & \\
\hline Party & 0.053 & $(0.030)$ & & 0.036 & $(0.026)$ & & 0.012 & $(0.014)$ & \\
\hline Ideology & -0.019 & $(0.053)$ & & 0.038 & $(0.045)$ & & -0.035 & $(0.024)$ & \\
\hline $\begin{array}{l}\text { Conversion without } \\
\text { explanation }\end{array}$ & 0.001 & $(0.120)$ & & 0.248 & $(0.093)$ & $* *$ & -0.061 & $(0.051)$ & \\
\hline Conversion with explanation & 0.725 & $(0.372)$ & & 0.084 & $(0.318)$ & & -0.021 & $(0.048)$ & \\
\hline Credibility & & & & & & & 0.041 & $(0.022)$ & $*$ \\
\hline Argument strength & & & & & & & 0.532 & $(0.027)$ & $\begin{array}{l}* * \\
*\end{array}$ \\
\hline Deference to science & 0.515 & $(0.050)$ & $\begin{array}{l}* * \\
*\end{array}$ & 0.347 & $(0.042)$ & $\begin{array}{l}* * \\
*\end{array}$ & & & \\
\hline $\begin{array}{l}\text { Conversion with explanation } \mathrm{x} \\
\text { Deference to science }\end{array}$ & -0.140 & $(0.079)$ & & 0.031 & $(0.067)$ & & & & \\
\hline
\end{tabular}

Note: $* p<0.05, * * p<0.01, * * * p<0.001$, Indirect effects based on 5,000 bootstrap samples with bias corrected confidence intervals. Conditional indirect effect of conversion without explanation through credibility, moderated by deference to science $=-.01(.01)(95 \%$ CI [-0.0202, 0.0009]). Conditional indirect effect of conversion with explanation through argument strength, moderated by deference to science $=.02(.04)(95 \%$ CI [-0.0617, 0.0931]). $N=596$. 
Table A3. Effect of conversion without explanation condition on attitudes about GM safety mediated through credibility and argument strength, moderated by climate change belief, controlling for age, gender, race, education, children under the age of 18, household income, political party, and political ideology

\begin{tabular}{|c|c|c|c|c|c|c|c|c|c|}
\hline \multirow{3}{*}{ (Constant) } & \multicolumn{3}{|c|}{ Credibility } & \multicolumn{3}{|c|}{ Argument Strength } & \multicolumn{3}{|c|}{ GMO Attitudes } \\
\hline & \multirow{2}{*}{$\frac{\mathrm{B}}{3.773}$} & \multicolumn{2}{|l|}{$(\mathrm{SE})$} & $\mathrm{B}$ & \multicolumn{2}{|l|}{$(\mathrm{SE})$} & \multirow{2}{*}{$\frac{B}{-2.135}$} & \multicolumn{2}{|c|}{$(\mathrm{SE})$} \\
\hline & & $(0.474)$ & $\begin{array}{l}* * \\
*\end{array}$ & 3.934 & $(0.401)$ & $\begin{array}{l}* * \\
*\end{array}$ & & $(0.176)$ & $\begin{array}{l}* * * \\
*\end{array}$ \\
\hline Age & 0.000 & $(0.003)$ & & -0.001 & $(0.003)$ & & -0.004 & $(0.001)$ & ** \\
\hline Gender & -0.132 & $(0.098)$ & & -0.106 & $(0.083)$ & & -0.094 & $(0.041)$ & $*$ \\
\hline Race & 0.370 & $(0.125)$ & $* *$ & 0.200 & $(0.106)$ & & 0.017 & $(0.053)$ & \\
\hline Education & 0.107 & $(0.030)$ & $\begin{array}{l}* * \\
*\end{array}$ & 0.068 & $(0.025)$ & ** & 0.025 & $(0.013)$ & * \\
\hline Children under 18 & 0.015 & $(0.057)$ & & -0.082 & $(0.049)$ & & -0.033 & $(0.023)$ & \\
\hline Income & -0.046 & $(0.027)$ & & -0.014 & $(0.023)$ & & -0.016 & $(0.011)$ & \\
\hline Party & 0.046 & $(0.034)$ & & 0.028 & $(0.029)$ & & 0.011 & $(0.014)$ & \\
\hline Ideology & -0.144 & $(0.059)$ & * & -0.050 & $(0.049)$ & & -0.037 & $(0.024)$ & \\
\hline $\begin{array}{l}\text { Conversion without } \\
\text { explanation }\end{array}$ & 1.516 & $(0.482)$ & $* *$ & 0.534 & $(0.408)$ & & -0.070 & $(0.052)$ & \\
\hline Conversion with explanation & 0.154 & $(0.116)$ & & 0.279 & $(0.098)$ & $* *$ & -0.030 & $(0.049)$ & \\
\hline Credibility & & & & & & & 0.044 & $(0.022)$ & $*$ \\
\hline Argument strength & & & & & & & 0.528 & $(0.027)$ & $\begin{array}{l}* * \\
*\end{array}$ \\
\hline Climate belief & 0.164 & $(0.082)$ & * & 0.018 & $(0.069)$ & & & & \\
\hline $\begin{array}{l}\text { Conversion without } \\
\text { explanation x Climate belief }\end{array}$ & -0.430 & $(0.482)$ & ** & -0.075 & $(0.112)$ & & & & \\
\hline
\end{tabular}

Note: $* p<0.05, * * p<0.01, * * * p<0.001$, Indirect effects based on 5,000 bootstrap samples with bias corrected confidence intervals. Index of moderated mediation of conversion without explanation through credibility, moderated by climate belief $=-.02(.01)(95 \%$ CI $[-0.0485$, 0.0016]). Index of moderated mediation of conversion with explanation through argument strength, moderated by climate belief $=-.04(.06)(95 \%$ CI $[-0.1446,0.0701]) . N=587$. 
Table A4. Effect of conversion with explanation condition on attitudes about GM safety mediated through credibility and argument strength, moderated by climate change belief, controlling for age, gender, race, education, children under the age of 18 , household income, political party, and political ideology

\begin{tabular}{|c|c|c|c|c|c|c|c|c|c|}
\hline & \multicolumn{3}{|c|}{ Credibility } & \multicolumn{3}{|c|}{ Argument Strength } & \multicolumn{3}{|c|}{ GMO Attitudes } \\
\hline & $\mathrm{B}$ & $(\mathrm{SE})$ & & $\mathrm{B}$ & $(\mathrm{SE})$ & & $\mathrm{B}$ & $(\mathrm{SE})$ & \\
\hline (Constant) & 4.678 & $(0.502)$ & $\begin{array}{l}* * \\
*\end{array}$ & 4.105 & $(0.422)$ & $\begin{array}{l}* * \\
*\end{array}$ & -2.135 & $(0.176)$ & $\begin{array}{l}* * * \\
*\end{array}$ \\
\hline Age & 0.000 & $(0.003)$ & & -0.001 & $(0.003)$ & & -0.004 & $(0.001)$ & $* *$ \\
\hline Gender & -0.137 & $(0.098)$ & & -0.116 & $(0.003)$ & & -0.094 & $(0.041)$ & $*$ \\
\hline Race & 0.385 & $(0.126)$ & $* *$ & 0.205 & $(0.104)$ & & 0.017 & $(0.053)$ & \\
\hline Education & 0.106 & $(0.030)$ & $\begin{array}{l}* * \\
*\end{array}$ & 0.069 & $(0.025)$ & $* *$ & 0.025 & $(0.013)$ & $*$ \\
\hline Children under 18 & 0.021 & $(0.057)$ & & -0.080 & $(0.049)$ & & -0.033 & $(0.023)$ & \\
\hline Income & -0.043 & $(0.027)$ & & -0.014 & $(0.023)$ & & -0.016 & $(0.011)$ & \\
\hline Party & 0.043 & $(0.034)$ & & 0.027 & $(0.027)$ & & 0.011 & $(0.014)$ & \\
\hline Ideology & -0.139 & $(0.059)$ & $*$ & -0.049 & $(0.049)$ & & -0.037 & $(0.024)$ & \\
\hline $\begin{array}{l}\text { Conversion without } \\
\text { explanation }\end{array}$ & -0.823 & $(0.122)$ & & 0.268 & $(0.103)$ & $* *$ & -0.070 & $(0.052)$ & \\
\hline Conversion with explanation & -0.824 & $(0.458)$ & & 0.081 & $(0.386)$ & & -0.030 & $(0.049)$ & \\
\hline Credibility & & & & & & & 0.044 & $(0.022)$ & $*$ \\
\hline Argument strength & & & & & & & 0.528 & $(0.027)$ & $\begin{array}{l}* * \\
*\end{array}$ \\
\hline Climate belief & -0.092 & $(0.091)$ & & -0.030 & $(0.077)$ & & & & \\
\hline $\begin{array}{l}\text { Conversion with explanation } \mathrm{x} \\
\text { Climate belief }\end{array}$ & 0.271 & $(0.127)$ & & 0.055 & $(0.107)$ & & & & \\
\hline
\end{tabular}

Note: $* p<0.05, * * p<0.01, * * * p<0.001$, Indirect effects based on 5,000 bootstrap samples with bias corrected confidence intervals. Index of moderated mediation of conversion without explanation through credibility, moderated by climate belief $=.01(.01)(95 \%$ CI $[0.0003,0.0356])$. Index of moderated mediation of conversion with explanation through argument strength, moderated by climate belief $=.03(.05)(95 \%$ CI $[-0.0783,0.1301]) . N=587$. 
Table A5. Effect of conversion without explanation condition on attitudes about GM safety mediated through credibility and argument strength, moderated by environmentalism, controlling for age, gender, race, education, children under the age of 18, household income, political party, and political ideology

\begin{tabular}{|c|c|c|c|c|c|c|c|c|c|}
\hline \multirow{3}{*}{ (Constant) } & \multicolumn{3}{|c|}{ Credibility } & \multicolumn{3}{|c|}{ Argument Strength } & \multicolumn{3}{|c|}{ GMO Attitudes } \\
\hline & \multirow{2}{*}{$\frac{B}{3.523}$} & \multicolumn{2}{|l|}{$(\mathrm{SE})$} & $\mathrm{B}$ & \multicolumn{2}{|l|}{$(\mathrm{SE})$} & \multirow{2}{*}{$\frac{B}{-2.126}$} & \multicolumn{2}{|l|}{$(\mathrm{SE})$} \\
\hline & & $(0.434)$ & $\begin{array}{l}* * \\
*\end{array}$ & 3.838 & $(0.366)$ & $\begin{array}{l}* * \\
*\end{array}$ & & $(0.175)$ & $\begin{array}{l}* * \\
*\end{array}$ \\
\hline Age & -0.001 & $(0.003)$ & & -0.001 & $(0.003)$ & & -0.004 & $(0.001)$ & $* *$ \\
\hline Gender & -0.172 & $(0.097)$ & & -0.131 & $(0.082)$ & & -0.098 & $(0.041)$ & $*$ \\
\hline Race & 0.388 & $(0.125)$ & $* *$ & 0.195 & $(0.105)$ & & 0.004 & $(0.053)$ & \\
\hline Education & 0.098 & $(0.030)$ & $* *$ & 0.068 & $(0.025)$ & $* *$ & 0.025 & $(0.013)$ & $*$ \\
\hline Children under 18 & 0.000 & $(0.056)$ & & -0.080 & $(0.049)$ & & -0.034 & $(0.023)$ & \\
\hline Income & -0.043 & $(0.027)$ & & -0.015 & $(0.023)$ & & -0.016 & $(0.012)$ & \\
\hline Party & 0.046 & $(0.034)$ & & 0.026 & $(0.029)$ & & 0.009 & $(0.014)$ & \\
\hline Ideology & -0.117 & $(0.059)$ & $*$ & -0.043 & $(0.050)$ & & -0.031 & $(0.025)$ & \\
\hline $\begin{array}{l}\text { Conversion without } \\
\text { explanation }\end{array}$ & 0.690 & $(0.441)$ & & 0.246 & $(0.371)$ & & -0.068 & $(0.051)$ & \\
\hline Conversion with explanation & 0.182 & $(0.115)$ & & 0.279 & $(0.098)$ & $* *$ & -0.034 & $(0.048)$ & \\
\hline Credibility & & & & & & & 0.048 & $(0.022)$ & $*$ \\
\hline Argument strength & & & & & & & 0.525 & $(0.026)$ & $\begin{array}{l}* * \\
*\end{array}$ \\
\hline Environmentalism & 0.162 & $0.049)$ & $* *$ & 0.031 & $(0.041)$ & & & & \\
\hline $\begin{array}{l}\text { Conversion without } \\
\text { explanation } \mathrm{x}\end{array}$ & & & & & & & & & \\
\hline Environmentalism & -0.126 & $(0.086)$ & & 0.010 & $(0.072)$ & & & & \\
\hline
\end{tabular}

Note: $* p<0.05, * * p<0.01, * * * p<0.001$, Indirect effects based on 5,000 bootstrap samples with bias corrected confidence intervals. Index of moderated mediation of conversion without explanation through credibility, moderated by climate belief $=-.01(.01)(95 \%$ CI $[-0.0245$, 0.0024]). Conditional indirect effect of conversion with explanation through argument strength, moderated by climate belief $=.00(.04)(95 \%$ CI $[-0.0773,0.0879]) . N=590$. 
Table A6. Effect of conversion with explanation condition on attitudes about GM safety mediated through credibility and argument strength, moderated by environmentalism, controlling for age, gender, race, education, children under the age of 18 , household income, political party, and political ideology

\begin{tabular}{|c|c|c|c|c|c|c|c|c|c|}
\hline \multirow{3}{*}{ (Constant) } & \multicolumn{3}{|c|}{ Credibility } & \multicolumn{3}{|c|}{ Argument Strength } & \multicolumn{3}{|c|}{ GMO Attitudes } \\
\hline & B & $(\mathrm{SE})$ & & B & $(\mathrm{SE})$ & & B & $(\mathrm{SE})$ & \\
\hline & 4.172 & $(0.459)$ & $\begin{array}{l}* * \\
*\end{array}$ & 3.985 & $(0.388)$ & $\begin{array}{l}* * \\
*\end{array}$ & -2.126 & $(0.175)$ & $\begin{array}{l}* * \\
*\end{array}$ \\
\hline Age & -0.001 & $(0.003)$ & & -0.001 & $(0.003)$ & & -0.004 & $(0.001)$ & $* *$ \\
\hline Gender & -0.170 & $(0.097)$ & & -0.133 & $(0.082)$ & & -0.098 & $(0.041)$ & $*$ \\
\hline Race & 0.391 & $(0.124)$ & $* *$ & 0.199 & $(0.105)$ & & 0.004 & $(0.053)$ & \\
\hline Education & 0.094 & $(0.030)$ & $* *$ & 0.066 & $(0.025)$ & $* *$ & 0.025 & $(0.013)$ & $*$ \\
\hline Children under 18 & 0.003 & $(0.055)$ & & -0.079 & $(0.048)$ & & -0.034 & $(0.023)$ & \\
\hline Income & -0.038 & $(0.027)$ & & -0.014 & $(0.023)$ & & -0.016 & $(0.012)$ & \\
\hline Party & 0.053 & $(0.034)$ & & 0.033 & $(0.029)$ & & 0.009 & $(0.014)$ & \\
\hline Ideology & -0.112 & $(0.059)$ & & -0.041 & $(0.050)$ & & -0.031 & $(0.025)$ & \\
\hline $\begin{array}{l}\text { Conversion without } \\
\text { explanation }\end{array}$ & 0.032 & $(0.122)$ & & 0.268 & $(0.103)$ & & -0.068 & $(0.051)$ & \\
\hline Conversion with explanation & -0.873 & $(0.420)$ & $*$ & -0.059 & $(0.355)$ & $* *$ & -0.034 & $(0.048)$ & \\
\hline Credibility & & & & & & & 0.048 & $(0.022)$ & $*$ \\
\hline Argument strength & & & & & & & 0.525 & $(0.026)$ & $\begin{array}{l}* * \\
*\end{array}$ \\
\hline Environmentalism & 0.037 & $(0.054)$ & & 0.005 & $(0.045)$ & & & & \\
\hline $\begin{array}{l}\text { Conversion with explanation } \mathrm{x} \\
\text { Environmentalism }\end{array}$ & 0.206 & $(0.079)$ & $*$ & 0.066 & $(0.068)$ & & & & \\
\hline
\end{tabular}

Note: $* p<0.05, * * p<0.01, * * * p<0.001$, Indirect effects based on 5,000 bootstrap samples with bias corrected confidence intervals. Index of moderated mediation of conversion without explanation through credibility, moderated by climate belief $=-.01(.01)(95 \% \mathrm{CI}[0.0010,0.0291])$. Conditional indirect effect of conversion with explanation through argument strength, moderated by climate belief $=.04(.04)(95 \%$ CI $[-0.0421,0.1171]) . N=590$. 


\section{Appendix B \\ Results without covariate adjustment}

Table B1. Effect of experimental conditions on attitudes about GM safety mediated through perceived credibility and argument strength, controlling for age and political party.

\begin{tabular}{|c|c|c|c|c|c|c|c|c|c|}
\hline \multirow[b]{3}{*}{ (Constant) } & \multicolumn{3}{|c|}{ Credibility } & \multicolumn{3}{|c|}{ Argument Strength } & \multicolumn{3}{|c|}{ GM Food Attitudes } \\
\hline & \multirow{2}{*}{$\begin{array}{l}b \\
4.620\end{array}$} & \multirow{2}{*}{$\begin{array}{l}(\mathrm{SE}) \\
(0.164)\end{array}$} & \multicolumn{2}{|r|}{$b$} & \multicolumn{2}{|l|}{ (SE) } & $b$ & \multicolumn{2}{|l|}{ (SE) } \\
\hline & & & $* * *$ & 4.240 & $(0.138)$ & $* * *$ & -2.352 & $(0.114)$ & $* * *$ \\
\hline Age & 0.001 & $(0.003)$ & & -0.001 & $(0.002)$ & & -0.003 & $(0.001)$ & $*$ \\
\hline Party & -0.015 & $(0.024)$ & & 0.002 & $(0.020)$ & & -0.004 & $(0.010)$ & \\
\hline $\begin{array}{l}\text { Conversion without } \\
\text { explanation }\end{array}$ & 0.037 & $(0.059)$ & & 0.130 & $(0.050)$ & $* *$ & -0.023 & $(0.025)$ & \\
\hline Conversion with explanation & 0.047 & $(0.037)$ & & 0.087 & $(0.031)$ & $*$ & -0.016 & $(0.016)$ & \\
\hline Credibility & & & & & & & 0.057 & $(0.021)$ & $* *$ \\
\hline Argument Strength & & & & & & & 0.531 & $(0.025)$ & $* * *$ \\
\hline
\end{tabular}

Table B1 reports the results while controlling only for age and party, which are included due to the results of the random assignment check. As with the covariate-adjusted model reported in the main text, when looking at perceived credibility, the mediation was not significant. There was no direct effect of conversion without explanation $(b=.04, p=.53)$, and no direct effect of conversion with explanation on attitudes about GM foods $(b=.05, p=.21)$. There was no indirect effect through perceived credibility for either the conversion without explanation condition (pointestimate $=0.0021(0.004), 95 \%$ CI $[-0.0042,0.0121])$ or the conversion with explanation condition (point-estimate $=0.003(0.002), 95 \%$ CI $[-0.0008,0.0093])$

Again reflecting the primary covariate-adjusted model results, when looking at argument strength, the mediation was supported. Both the conversion without explanation condition $(b=.13$, $p<0.01)$, and the conversion with explanation $(b=.09, p<0.05)$, significantly increased the 
perceived argument strength. The results indicate that the conversion without explanation had a positive indirect effect on perceived argument strength (point estimate $=0.069(0.027), 95 \% \mathrm{CI}$ $[0.0168,0.1216])$, as did the conversion with explanation condition (point estimate $=0.046(0.017)$, $95 \%$ CI $[0.0148,0.0816])$. In sum, there were no substantive differences between covariate-adjusted and non-covariate adjusted models.

Table B2. Effect of experimental conditions on attitudes about GM safety mediated through attribution and argument strength, controlling for age and political party.

\begin{tabular}{|c|c|c|c|c|c|c|c|c|c|}
\hline \multirow[b]{3}{*}{ (Constant) } & \multicolumn{3}{|c|}{ Attribution } & \multicolumn{3}{|c|}{ Argument Strength } & \multicolumn{3}{|c|}{ GM Food Attitudes } \\
\hline & \multirow{2}{*}{$\begin{array}{l}b \\
4.626\end{array}$} & \multirow{2}{*}{$\begin{array}{l}(\mathrm{SE}) \\
(0.166)\end{array}$} & \multicolumn{2}{|r|}{$b$} & \multicolumn{2}{|l|}{$(\mathrm{SE})$} & $b$ & \multicolumn{2}{|l|}{ (SE) } \\
\hline & & & $* * *$ & 4.246 & $(0.138)$ & $* * *$ & -2.389 & $(0.116)$ & $* * *$ \\
\hline Age & 0.010 & $(0.003)$ & & -0.001 & $(0.002)$ & & -0.004 & $(0.001)$ & $*$ \\
\hline Party & -0.056 & $(0.025)$ & & 0.001 & $(0.020)$ & & -0.005 & $(0.010)$ & \\
\hline $\begin{array}{l}\text { Conversion without } \\
\text { explanation }\end{array}$ & -0.034 & $(0.060)$ & & 0.138 & $(0.050)$ & $* *$ & -0.022 & $(0.025)$ & \\
\hline Conversion with explanation & 0.028 & $(0.038)$ & & 0.089 & $(0.031)$ & $* *$ & -0.013 & $(0.016)$ & \\
\hline Attribution & & & & & & & 0.071 & $(0.019)$ & $* * *$ \\
\hline Argument Strength & & & & & & & 0.530 & $(0.023)$ & $* * *$ \\
\hline
\end{tabular}

Note: ${ }^{*} p<0.05, * * p<0.01,{ }^{* * *} p<0.001 . N=638$

Table B2 reports the results substituting attribution for credibility, while controlling only for age and party, which are included due to the results of the random assignment check. As with the covariate-adjusted model reported in the main text, when looking at attribution, the mediation was not significant. There was no direct effect of conversion without explanation $(b=-.02, p=.39)$, and no direct effect of conversion with explanation on attitudes about GM foods $(b=-.01, p=.41)$. There was no indirect effect through attribution for either the conversion without explanation condition (point-estimate $=-0.0025(0.004), 95 \%$ CI $[-0.0122,0.0053])$ or the conversion with explanation condition (point-estimate $=0.0020(0.002), 95 \%$ CI $[-0.0032,0.0089])$. 
Again reflecting the covariate-adjusted model results, when looking at argument strength, the mediation was supported. Both the conversion without explanation condition $(b=.14, p<$ $0.01)$, and the conversion with explanation $(b=.09, p<0.01)$, significantly increased the perceived argument strength. The results indicate that the conversion without explanation had a positive indirect effect on perceived argument strength (point estimate $=0.073(0.027), 95 \% \mathrm{CI}[0.0200$, $0.1258]$ ), as did the conversion with explanation condition (point estimate $=0.047(0.017), 95 \% \mathrm{CI}$ $[0.0145,0.0809])$. In sum, there were no substantive differences between covariate-adjusted and non-covariate adjusted models. 